\title{
Satellite geodesy tools for ground subsidence and associated shallow faulting hazard assessment in central Mexico
}

\author{
E. Cabral-Cano ${ }^{1}$, D. Solano-Rojas ${ }^{2}$, T. Oliver-Cabrera ${ }^{2}$, S. Wdowinski ${ }^{2}$, E. Chaussard ${ }^{3}$, \\ L. Salazar-Tlaczani ${ }^{1}$, F. Cigna ${ }^{4}$, C. DeMets ${ }^{5}$, and J. Pacheco-Martínez ${ }^{6}$ \\ ${ }^{1}$ Departamento de Geomagnetismo y Exploración, Instituto de Geofísica, Universidad Nacional Autónoma de \\ México, México DF, 04510, México \\ ${ }^{2}$ Rosenstiel School of Marine and Atmospheric Science, University of Miami, Miami, FL 33149, USA \\ ${ }^{3}$ Dept. of Earth and Planetary Science, University of California Berkeley, Berkeley, USA \\ ${ }^{4}$ British Geological Survey, Earth Hazards \& Observatories, Earth and Planetary Observation and Monitoring, \\ Nottingham, UK \\ ${ }^{5}$ Department of Geoscience, University of Wisconsin-Madison, Madison, Wisconsin 53706, USA \\ ${ }^{6}$ Departamento de Construcción y Estructuras, Universidad Autónoma de Aguascalientes, \\ Aguascalientes, México \\ Correspondence to: E. Cabral-Cano (ecabral@geofisica.unam.mx)
}

Published: 12 November 2015

\section{Motivation}

While subsidence has affected Mexico City for over a century, other cities in central Mexico have been subjected to ground subsidence since the 1980's, as a result of their large urban expansion, population increase and aggressive groundwater extraction rates. The continuous ground subsidence results in severe damage to urban infrastructure and civil structures. Unfortunately the damage cost assessment and vulnerability are difficult to evaluate, because of the variable geographic extent and the time-continuous nature of the process, which have different characteristics than other phenomena characterized by localized, short duration events such as earthquakes or floodings with better media coverage.

A recent SBAS survey based on ALOS-1 PALSAR data along central Mexico (Chaussard et al., 2014) indicates that this process is rapidly becoming a widespread phenomenon that potentially affects a population over 25 million inhabitants. InSAR-derived information and its cartographic products from geodetic imaging will be key to develop a better groundwater extraction strategy in areas that undergo extreme subsidence rates, propose better mitigation strategies and ultimately improve water resource management.

In Mexico, subsidence induced damage to houses or other urban infrastructure is not eligible for federal emergency re- lief funds, because it is not considered a naturally occurring process but rather an anthropogenically induced one. Furthermore, this phenomenon is localized and usually managed only at the local city or county-level administrations, while most other large impact natural hazards, as earthquakes, volcano eruptions, or flooding events, are usually managed by federal agencies. This work is aimed towards a better recognition of subsidence as a major hazard in Mexico, assess the number of inhabitants affected and the spatial extent of the subsiding areas affected by this process. The space-based subsidence imaging can be used to improve water resources management (e.g. Hernández-Espriú et al., 2014) in an area that comprises a number of rapidly growing urban areas and assess its associated surface faulting geological hazard.

We envision that this work will serve as a test case where water-usage policy makers can have access to custom cartographic products suitable for data fusion and data mining from third party regional water management agencies databases and include satellite geodesy imaging techniques as a routine monitoring technique for aquifer assessment and its sustainable management. Within this context, space geodetic techniques, most notably InSAR complemented by GPS are quite suitable for this task. InSAR provides an unsurpassed synoptic view of the earth's dynamic surface; for 

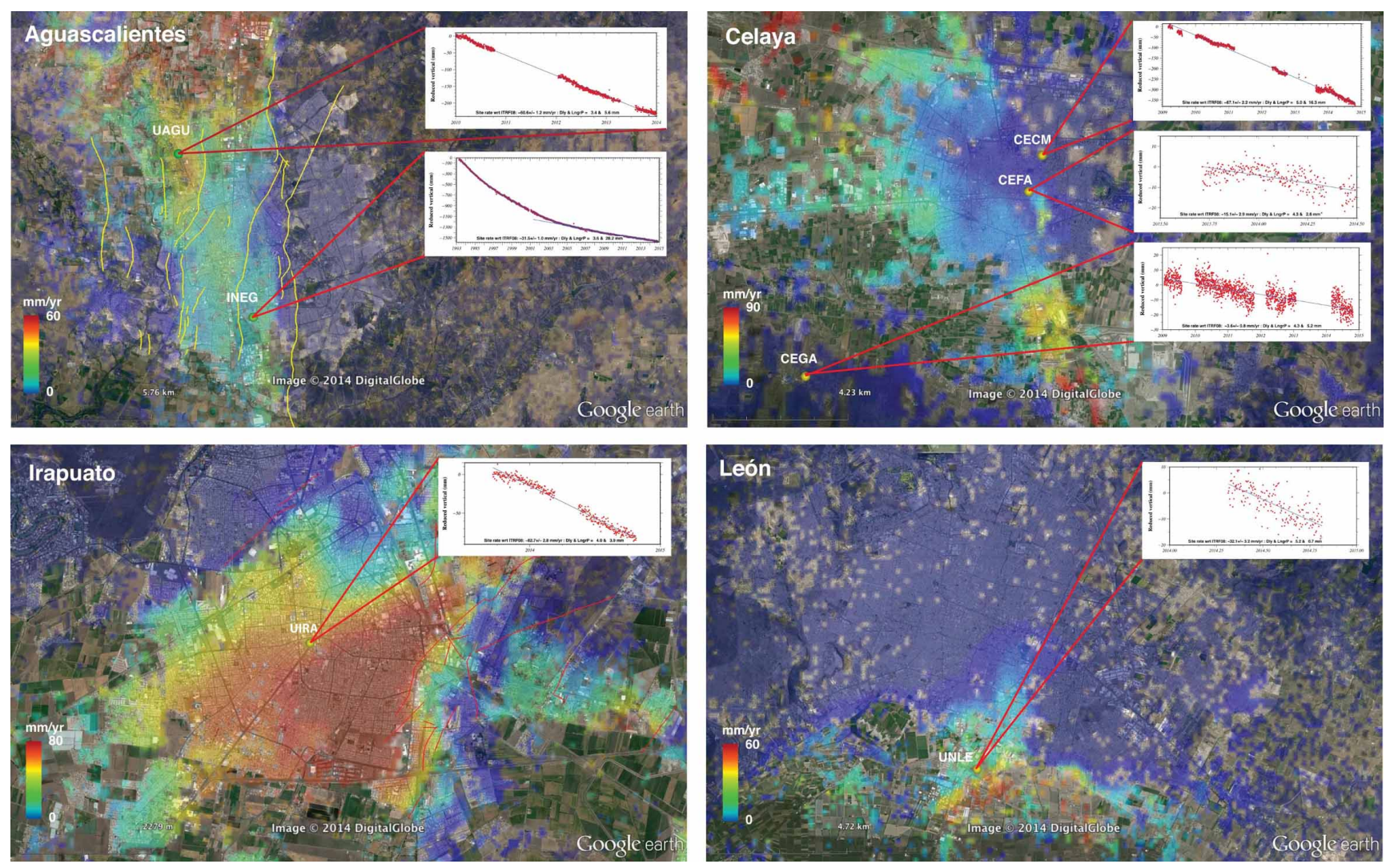

Figure 1. Ground subsidence velocity maps (modified from Chaussard et al., 2014) and cGPS vertical component time series for the cities of Aguascalientes, Celaya, Irapuato, and León.

example, the most recent InSAR analysis in central Mexico (Chaussard et al., 2014) shows that land subsidence can be identified in 17 cities. However, different satellite sensors and sometimes widely spaced data availability make it difficult to derive long-term time series, or measure rapid changes or nonlinear variations of subsidence velocities. To alleviate this situation, higher temporal resolution subsidence observations of associated fault motion has been pursued using continuously operating GPS stations. As a complement to the InSAR observations, we have developed a GPS network that covers 6 urban centers to better characterize the temporal variability of ground subsidence, using several processing schemes that include both real-time solutions using RTNet as well as daily solutions with IGS precise orbits using Gipsy-Oasis.

Our current efforts are aimed to evaluate the applicability of high spatial resolution, space-based subsidence imaging based on operational SAR sensors (namely TSX and ALOS2) to improve water resources exploitation and better management of these resources within a region that comprises a number of rapidly growing urban areas. In this work we are presenting several cases of rapidly subsiding cities to their respective municipal and state level administrations in order to set the stage for a future routine use of remote sensed data for the long term management of hydrologic resources
Another important objective is to provide an independent observation tool for estimating structural damage in the urban areas to be studied. The accumulated subsidence in Mexico City has resulted in continuous damage to buildings and infrastructure, which is hard to monitor. In our previous PSI studies we were able to refine methodologies to define potential areas of subsidence associated faulting based on the InSAR horizontal gradient analysis (Cabral-Cano et al., 2010a). We could also detect different subsidence behaviors occurring in different building types due to either suboptimal foundation calculations or evaluate longer term results of subsidence mitigation civil works in colonial-time historic buildings (Osmanoglu et al., 2011). Recent SBAS analysis throughout the region (Fig. 1) indicates substantial subsidence magnitudes either in their central downtown areas or nearby suburban developments.

\section{Significance}

Study of the subsidence phenomena, its consequences and mitigation efforts in Mexico have been carried out by different entities and are thus detached from each other. Academic institutions have undergone the study of regional subsidence and the aquifer vulnerability, while municipal wa- 

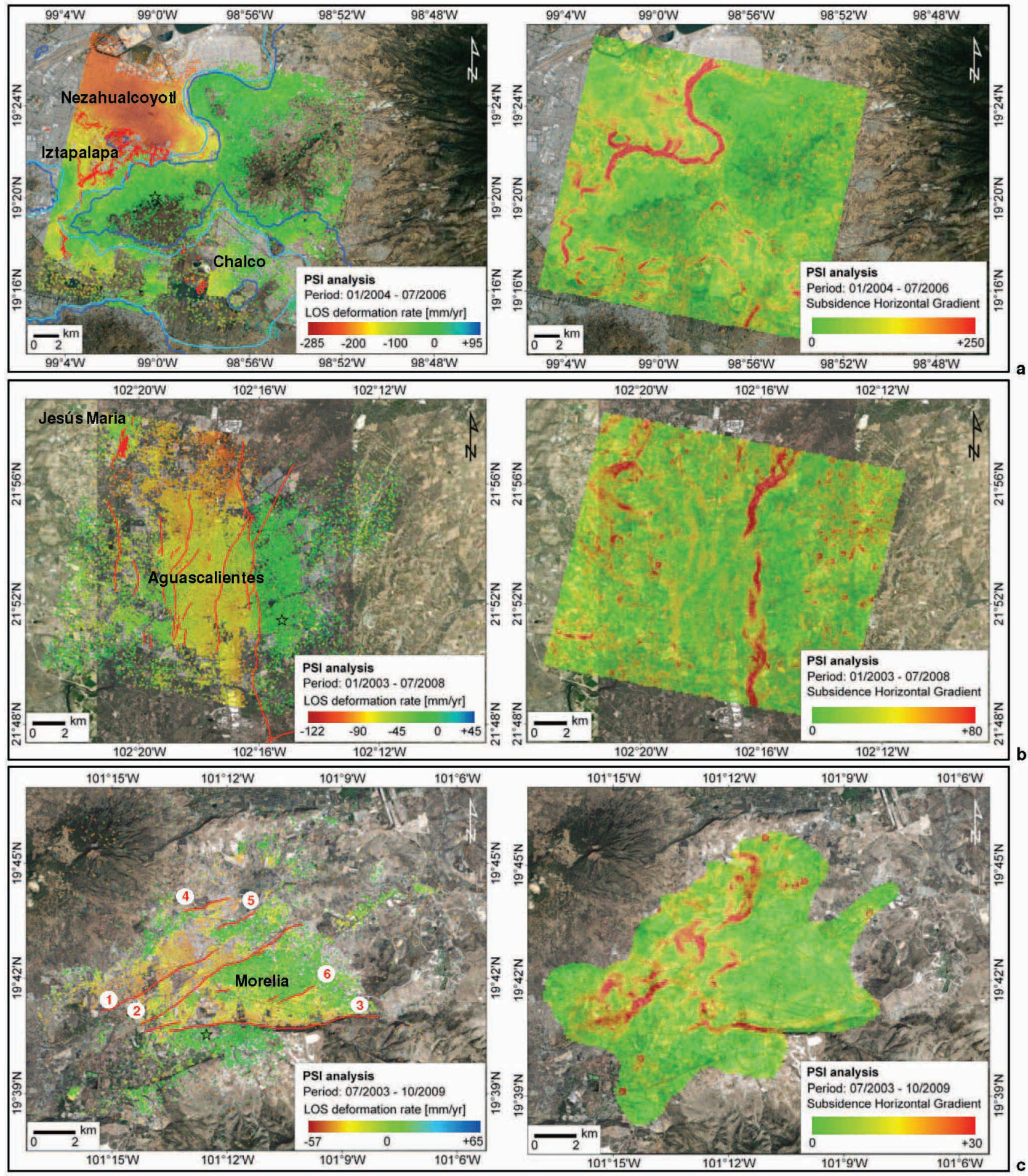

Figure 2. LOS deformation rates (left panels) and subsidence horizontal gradients (right panels) in the urban areas of Chalco (a), Aguascalientes (b) and Morelia (c) in Central Mexico, using ENVISAT 2004-2006, 2003-2008 and 2003-2009 data, respectively (after Cigna et al., 2011). Red lines show mapped faults. The geotechnical zonation of Chalco (a) shows the boundaries of lacustrine (light blue lines) and transitional (blue lines) geotechnical units. InSAR derived ground subsidence velocity maps (left panels) were processed using a horizontal subsidence gradient analysis approach that provides an excellent tool to discriminate areas with high potential of surface faulting (right panels). Notice the close correspondence between mapped faults on the corresponding left panels and the high gradient areas shown on the left panels. Further data merging with population, hydrology and meteorology data sets allow the creation of risk maps using a simple risk matrix (see Fig. 3). 


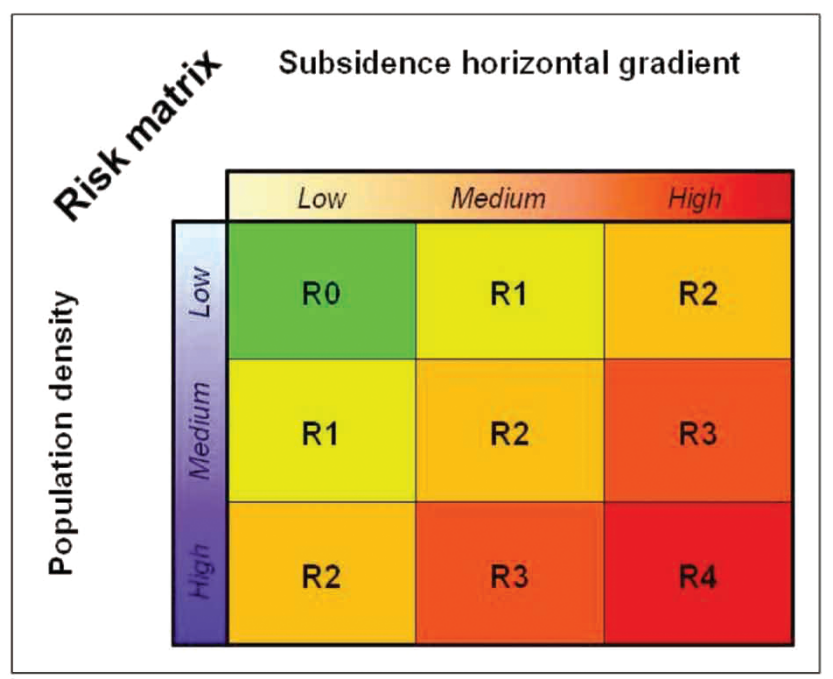

Figure 3. Risk matrix used to produce the hazard zonation map shown on Fig. 4, relating subsidence gradient and population density.

a)

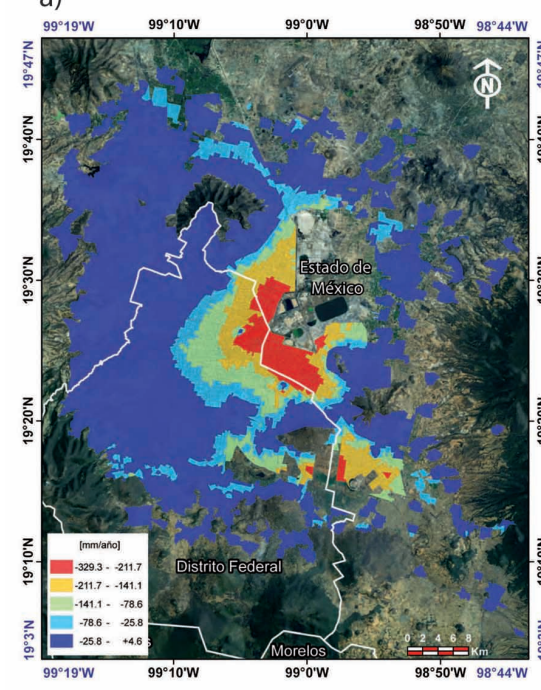

b)

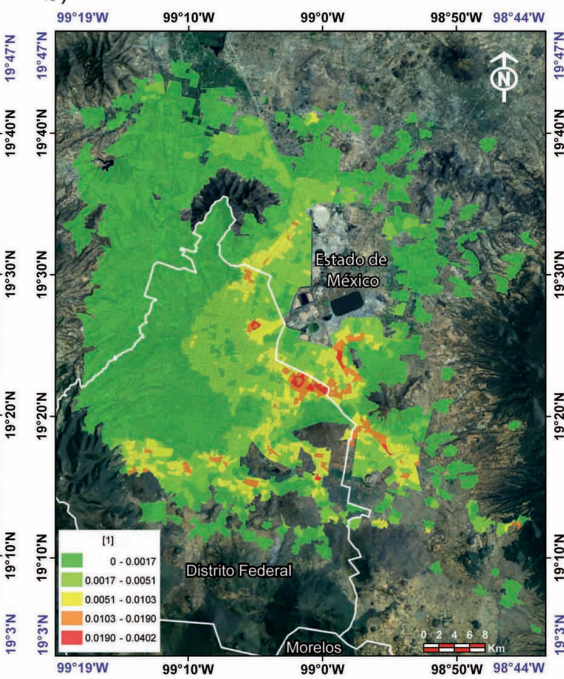

c)
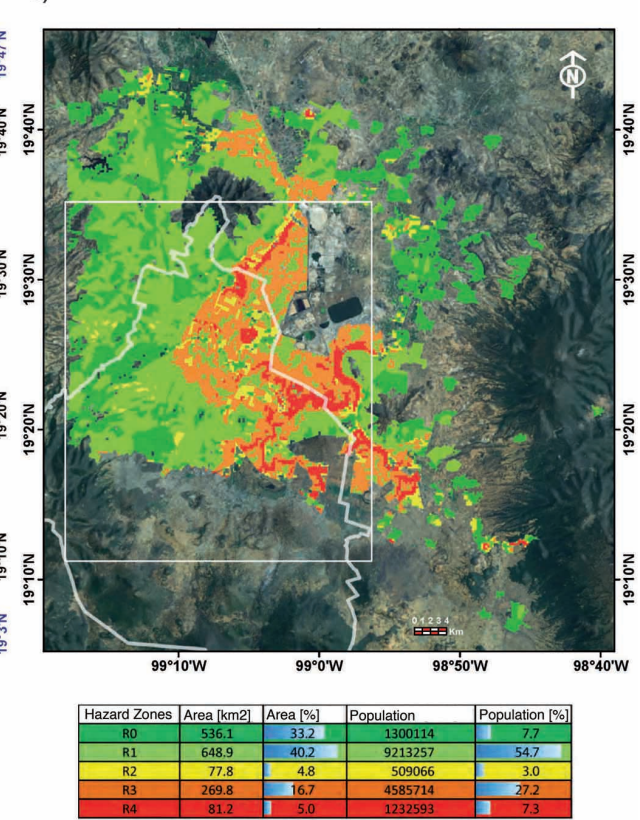

Figure 4. Example of hazard zonation for surface faulting associated to ground subsidence in the Mexico City Metropolitan Area. Left panel: ground subsidence magnitude. Central panel: subsidence horizontal gradient zonation. Right panel: hazard zonation. In this example, $21.7 \%$ $\left(351.0 \mathrm{~km}^{2}\right)$ of the city's urban area and $34.5 \%$ of its population (4 709305 inhabitants) are under a high to very high risk of being affected by faulting associated with subsidence (right panel).

ter management agencies are concerned with providing water for the continuously growing. However this scenario implies that municipal water agencies have long ignored that extreme aquifer exploitation and poor management conveys a heavy financial impact due to damage to housing, and urban infrastructure in ground subsidence affected areas. Moreover, mitigation efforts focus their efforts on the short-term engineering solutions but tend to ignore the driving force.
This work is aimed to: (a) showcase a methodological approach to use both imaging remote sensing and GPS data to provide a detailed panorama of the spatial and time variability of subsidence, and use products such as the horizontal subsidence gradient from InSAR derived using several cities in central Mexico as an example and provide an initial assessment of hazard due to surface faulting associated with ground subsidence. (b) Construct the observational capabil- 
ity to generate geodetic-hydrological datasets that will serve to better model future scenarios and foster a sustainable use of water resources. (c) Define vulnerable areas of subsidence related faulting, create hazard maps and help refine municipal land use codes for the studied metropolitans in such a way that water management agencies, have high resolution cartographic products that will serve for the development of a long term, sustainable strategy and mitigation effort plans that will eventually restore aquifers and stop ground subsidence.

\section{Approach}

Our approach for hazard assessment of shallow faulting associated with subsidence (Fig. 2) is based on ground subsidence derived from InSAR vertical displacement data following Cabral-Cano et al. (2011). These data were further analyzed using a horizontal subsidence gradient analysis approach (Cabral-Cano et al., 2010a; Fig. 2 right panels).

Our previous studies in Mexico City (Cabral-Cano et al., 2008; Osmanoglu et al., 2011) and Morelia (Cigna et al., 2012) highlighted the fact that spatial gradients of land subsidence, rather than magnitude, are the primary factors to be analyzed for subsidence hazard assessment (Cabral-Cano et al., 2010a, b). Differential ground displacement induces shear stresses in urban structures and consequent development of fractures and damages. This parameter can therefore be used to qualitatively assess subsidence hazard and to perform, together with the analysis of the elements at risk and their vulnerability, a qualitative mapping of subsidence risk that should be necessarily taken into account for any future urban development plans and land use codes As shown on Fig. 2, This provides an excellent tool to discriminate areas with high potential of surface faulting. We then combine these hazard indicators with the local population information from census data, through a risk assessment matrix. To compute the subsidence gradients, surface displacement data points from the Persistent scatterer interferometric analysis is gridded into a regular mesh, after which the non-dimensional horizontal subsidence gradient is then computed for each one of the grid cells (Cabral-Cano et al., 2011; Cigna et al., 2011; see Fig. 2). Hazard and elements at risk can be then combined through a 2-D risk matrix (Fig. 3), assuming that the coexistence of high differential subsidence rates and high density of population leads to higher levels of risk. The combination of these products with socioeconomic and population data sets allow the creation of risk maps such as the one shown on Fig. 4. The resulting cartographic products can be integrated into a geographical information system suitable for distribution to local, state and federal as a geocoded, high- resolution product suitable for detailed spatial analysis and better hazard assessment.

These ground subsidence risk maps (e.g. Fig. 4) represent valuable decision elements to help local authorities design
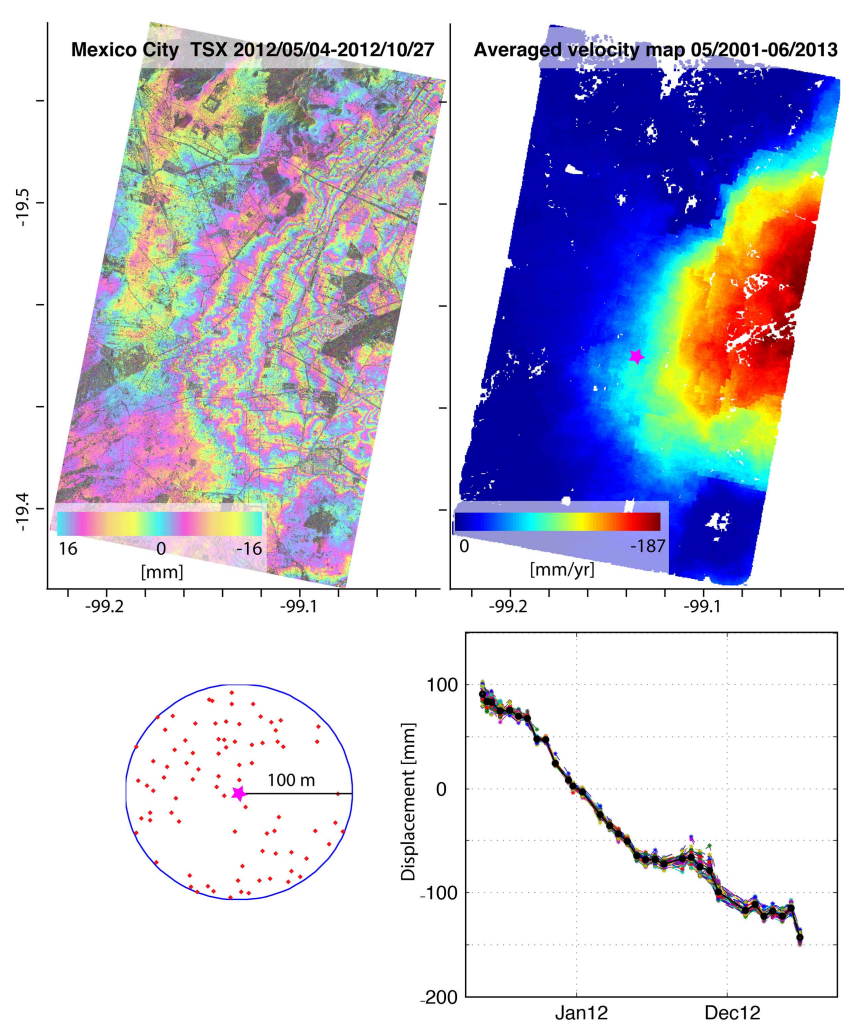

Figure 5. Top left panel: wrapped interferogram showing displacement in Mexico City from 4 May to 27 October 2012. Top right panel: averaged velocity map from PS analysis in the study area from mid 2011 to mid 2013. The star shows the location where time series were extracted. Bottom left panel: PS density in a radius of $100 \mathrm{~m}$ around the point selected. Bottom right: time series of the PS showed in the left panel respect to a master SAR scene from 6 February 2012.

the best risk mitigation and management strategies for cities under intense subsidence. On the other hand, the analysis of the subsidence gradient map can also be successfully used as an indicator of hazard and to support the planning of future development and land use zoning in urban areas. This approach allows the definition of zones where new development and urban expansion should be discouraged because of their highest levels of differential subsidence.

While InSAR based information provides an unsurpassed synoptic analysis, in some cases different satellite sensor and sometimes widely spaced data availability make it difficult to derive long-term time series, or measure rapid changes or nonlinear variations of subsidence velocities. In order to accommodate for these deficiencies, the higher temporal resolution subsidence observations has been pursued using continuously operating GPS stations. For this purpose, we have developed a continuous GPS network that covers 6 urban centers (e.g. Fig. 1) to detect short duration variations using different processing schemes that include both real-time solutions using RTNet as well as daily solution using Gipsy- 
Oasis. These stations also serve as validation and calibration sites for InSAR analysis. Data from these stations is open and freely available at the TLALOCNet data archive (http://tlalocnet.udg.mx).

\section{Continuous ground subsidence monitoring}

The continuous nature of the subsidence process necessary requires frequent updates on velocity and timely detection of any ground subsidence acceleration. New SAR sensors availability facilitate this task by providing new opportunities for ground subsidence velocity map updates. Our work in progress includes the updated subsidence analysis using TerraSAR-X and ALOS-2 data. For the Stripmap mode scenes from Mexico City obtained by the TerraSAR-X satellite (Fig. 5), we used the Stanford Method for Persistent Scatterers (StaMPS) to extract ground deformation displacements from time series of 35 Synthetic Aperture Radar acquisitions from mid 2011 to mid 2013. Our results include displacement maps with a ground resolution close to $3 \mathrm{~m}$, and derived Persistent Scatterers time series. In Fig. 5 we observe very localized deformation patterns in some areas of the city; this allows us to analyze the vulnerability of some structures to differential deformation as well as ground failure. Our field observations give us a reference of the importance of identifying areas with increased vulnerability to suffer deformation and stress due to differential ground subsidence.

\section{Conclusions}

Ground subsidence hazard analysis in central Mexico urban areas show that this process affects several cities and a substantial percentage of their inhabitants. However due to the rapid urban expansion and the corresponding continuous overexploitation of their underlying aquifers, the process seems unlikely to be be reversed in the short term. This situation requires constant subsidence monitoring. The new generation of SAR satellite sensors and free data policies have the potential for providing with the necessary data for a continuous subsidence monitoring effort.

Acknowledgements. S. Wdowinski and E. Cabral-Cano acknowledge support through NASA-ROSES grant NNX12AQ08G. E. Cabral-Cano is supported by UNAM-PAPIIT projects IN1042132 , and IN109315-3. This material is partly based on data provided by the UNAVCO Facility with support from the National Science Foundation (NSF) under award EAR-1338091.

\section{References}

Cabral-Cano, E., Dixon, T. H., Miralles-Wilhelm, F., SánchezZamora, O., Díaz-Molina, O., and Carande, R. E.: Space Geodetic Imaging of Rapid Ground Subsidence in México City, B. Am. Geol.1 Soc., 120, 1556-1566, doi:10.1130/B26001.1, 2008.

Cabral-Cano, E., Osmanoglu, B., Dixon, T., Wdowinski, S., DeMets, C., Cigna, F., and Díaz-Molina, O.: Subsidence and fault hazard maps using PSI and permanent GPS networks in central Mexico, Int. Assoc. Hydrol. Sci., 339, 255-259, 2010a.

Cabral-Cano, E., Arciniega-Ceballos, A., Díaz-Molina, O., Cigna, F., Osmanoglu, B., Dixon, T., Demets, C., Vergara-Huerta, F., Garduño-Monroy, V. H., Ávila-Olivera, J. A., and HernándezQuintero, E.: Is there a tectonic component on the subsidence process in Morelia, Mexico?, Int. Assoc. Hydrol. Sci., 339, 164169, 2010b.

Cabral-Cano, E., Diaz Molina, O., and Delgado-Granados, H.: Subsidencia y Mapas de Peligro por Fallamiento Superficial: Un Ejemplo en el área Nororiental de la Zona Metropolitana de la Ciudad de México, Bol. Sociedad Geol. Mex., 63, 53-60, 2011.

Cigna, F., Cabral-Cano, E., Osmanoğlu, B., Dixon, T. H., and Wdowinski S.: Detecting subsidence-induced faulting in Mexican urban areas by means of Persistent Scatterer Interferometry and subsidence horizontal gradient mapping. In: IEEE International, Geoscience \& Remote Sensing Symposium (IGARSS) 2011, Vancouver, Canada, 24-029 July 2011, 2125-2128, doi:10.1109/IGARSS.2011.6049585, 2011.

Cigna, F., Osmanoğlu, B., Cabral-Cano, E., Dixon, T. H., ÁvilaOlivera, J. A., Garduño-Monroy, V. H., DeMets, C., and Wdowinski, S.: Monitoring land subsidence and its induced geological hazard with Synthetic Aperture Radar Interferometry: a case study in Morelia, Mexico, Remote Sens. Environ., 117, 146-161, doi:10.1016/j.rse.2011.09.005, 2012.

Chaussard, E., Wdowinski, S., Cabral-Cano, E., and Amelung, F.: Land subsidence in central Mexico detected by ALOS InSAR time-series, Remote Sens. Environ., 140, 94-106, doi:10.1016/j.rse.2013.08.038, 2014.

Hernández-Espriú, A., Reyna-Gutiérrez, J. A., Sánchez-León, E., Cabral-Cano, E., Carrera-Hernández, J., Martínez-Santos, P., Macías-Medrano, S., Falorni, G., and Colombo, D.: DRASTICSg Model, a new extension to the standard DRASTIC approach for mapping groundwater vulnerability in urban aquifers subject to differential land subsidence. Application to Mexico City, Hydrogeol. J., 22, 1469-1485, doi:10.1007/s10040-014-1130-4, 2014.

Osmanoglu, B., Dixon, T. H., Wdowinski, S., Cabral-Cano, E., and Jiang, Y:: Mexico City Subsidence Observed with Persistent Scatterer InSAR, Int. J. Appl. Earth Obs., 13, 1-12, doi:10.1016/j.jag.2010.05.009, 2011. 